\title{
Artigo
}

REsumo
As representações maternas en-
globam expectativas, fantasias e
desejos da mãe sobre o bebê, as-
sim como os aspectos transgera-
cionais ligados a isso. O objeti-
vo do presente artigo é abordar
essas representações, destacando
as representaçôs da mulher so-
bre a sua própria mãe e sobre o
bebê. Além disso, buscou-se
apresentar as possibilidades de
avaliação e intervenção clínica
sobre essas representações, segun-
do a perspectiva psicanalitica.
Ressalta-se que a exploração das
representações maternas constitui
uma importante ferramenta da
clínica pais-bebê, auxiliando na
melhoria da qualidade dessa
relação. Em decorrência disso,
tal investigação poderia ser mais
utilizada tanto no contexto cli-
nico como de pesquisa.
Descritores: representações
maternas; psicanálise; relação
mãe-criança.

\section{REPRESENTAÇÕES MATERNAS: ASPECTOS TEÓRICOS E POSSIBILIDADES DE AVALIAÇÃO E INTERVENÇÃO CLIINICẢ}

\author{
Stela Araújo Cabral \\ Daniela Centenaro Levandowski
}

\section{Introdução}

Al vida fantasmática da mãe e suas repercussões na relação com o bebê encontram-se retratadas nos trabalhos de vários autores psicanalíticos, desde Freud (1914/1996b), a partir de diferentes perspectivas (Bick, 1964/1987; Bion, 1962/1991;

Psicóloga clínica. Mestre em Psicologia Clínica (Universidade do Vale do Rio dos Sinos).

- Psicóloga. Docente e pesquisadora do Departamento de Psicologia da Universidade Federal de Ciências da Saúde de Porto Alegre-RS. 
Cramer \& Palácio-Espasa, 1993; Fraiberg, Adelson \& Shapiro, 1975; Klein, 1952/1987; Lebovici, 1987, 1996, 1998; Winnicott, 1956/ 2000, 1987/2006). A percepção do papel fundamental exercido pelas representações maternas na maneira de a mãe agir com o bebê constitui um campo atual de estudos e se insere como um dos temas de investigação da situação clínica pais-bebê, inicialmente inspirada pelas concepções psicanalíticas (Wendland, 2001). Contudo, apesar da importância do tema, as influências dessas representações no desenvolvimento da criança foram verdadeiramente consideradas pela psiquiatria infantil somente a partir dos anos 70 (Cramer \& Palácio-Espasa, 1993).

O presente artigo tem por objetivo abordar as representações maternas, destacando as representações sobre a sua própria mãe e sobre o bebê. Também buscou apresentar as possibilidades de avaliação e intervenção clínica sobre essas representações, segundo a perspectiva psicanalítica. A fim de situar o tema em estudo, inicialmente são tecidas algumas considerações sobre o conceito representação na perspectiva psicanalítica. Após, detalha-se o conceito representação materna e, por fim, são apresentadas algumas possibilidades de avaliação e intervenção clínica sobre essas representações nessa mesma perspectiva.

\section{Algumas considerações sobre o conceito "representação" na psicanálise}

Ressalta-se, inicialmente, que as considerações aqui mencionadas sobre representação têm como objetivo destacar o seu valor tópico, explicitando sua dimensão nas instâncias psíquicas inconsciente, pré-consciente e consciente, a partir das concepções de Freud. Sendo assim, não se pretende, neste trabalho, apresentar um estudo sobre o conceito "representação" na obra de Freud, tampouco na psicanálise, já realizado por outros autores (Caropreso, 2003, 2008; Munhoz, 2009; Thá, 2004), mas apresentar algumas possíveis definições do conceito e enfatizar alguns aspectos que contribuem para a compreensão e a investigação das representações maternas.

Segundo Laplanche e Pontalis (2008, p. 495), representação pode ser conceituada como "aquilo que se representa, o que forma conteúdo concreto de um ato de pensamento e, em especial, a reprodu- 
ção de uma percepção anterior". Esse conceito foi descrito e investigado pela psicanálise a partir de Freud (1891), em seus estudos sobre a afasia. A princípio, esse autor considerou que tal fenômeno fazia parte estritamente do campo da consciência, uma vez que a psicanálise, no início, estava sendo construída de acordo com o parâmetro das leis físicas postuladas pelas ciências biológicas $(\mathrm{Ca}-$ ropreso, 2003). Posteriormente, no Projeto para uma Psicologia Científica, publicado em 1950, Freud (1895) redimensionou a sua concepção sobre representação, dissociando-a do campo consciente, passando a situá-la como um fenômeno do campo inconsciente (Caropreso, 2003, 2008).

Contudo, foi em 1915, em suas considerações sobre o inconsciente, que o conceito representação foi mais aprofundado e aprimorado por Freud, sendo definido como uma categoria fundamental da experiência psíquica (Almeida, Ataíde, Nascimento, Pires \& Silva, 2003). Para ele, as representações seriam unidades mentais compostas fundamentalmente de imagens psíquicas de objetos, bem como sensações exteriores ao aparelho psíquico. As mesmas estariam relacionadas com redes associativas, que manifestariam sua ocorrência na realidade externa e seriam capazes de representar também relações e eventos (Thá, 2004).

Diante de tal definição, é possível perceber o quão complexo é esse fenômeno, e onde ele se situa: no 
campo consciente, inconsciente, ou em ambos. Green (1990) refere que a representação não faz parte apenas do inconsciente, do que está reprimido, mas também do consciente. Ela se transforma a fim de que possa ser aceita pelo consciente. Quando isso acontece, não se tem apenas representações de coisas inconscientes, mas representações de palavras, que derivam da união da representação de coisa, descrita por Freud (1915/ 1996c), com o afeto (Munhoz, 2009).

De fato, Freud (1915/1996c) destacou que a representação de coisa pertenceria exclusivamente à instância psíquica inconsciente. Tais representações ficaram impressas na mente quando ainda não havia palavras para nomeá-las e seriam como um arquivo sensorial, que abriga fragmentos de antigas percepções, pertencendo essencialmente ao campo visual (Laplanche \& Pontalis, 2008). Já a representação de palavra (Freud, 1915/ 1996c) faria parte da instância psíquica pré-consciente, e funcionaria como um arquivo de registro do conhecimento e recordações não atuais, pertencendo ao campo acústico. Esta faria uma conexão entre a verbalização e a tomada de consciência, pois seria a partir de uma imagem verbal que uma imagem mnésica poderia chegar à instância consciente. Isso promoveria a passagem da identidade de percepção (processo primário) para a identidade de pensamento (processo secundário) (Laplanche \& Pontalis, 2008).
Ressaltando o valor tópico da representação, Freud (1915/1996c) referiu que a representação de coisa mais a representação de palavra correspondente fariam parte das representações conscientes, enquanto que a representação de coisa seria apenas uma representação inconsciente. A ligação entre as duas caracterizaria o sistema pré-consciente-consciente (Laplanche $\&$ Pontalis, 2008).

O conceito de representação também foi utilizado e aprimorado por outros autores psicanalíticos depois de Freud, a partir de diferentes perspectivas (por ex., Aulagnier, 1994; Green, 1990). Da mesma forma, sua investigação na psicanálise se estendeu ao campo da relação pais-bebê, no qual são analisadas, dentre outras representações, as representações maternas, devido à sua importante repercussão no desenvolvimento psíquico da criança (Cramer \& PalácioEspasa, 1993; Golse, 2003; Lebovici, 1983/1987). Assim, as representações maternas têm por base alguns aspectos mencionados sobre a representação, porém, sua investigação está focada especificamente no contexto da maternidade.

\section{Conceituando representação materna}

Precedendo o nascimento do bebê, ainda durante a gestação e antes mesmo de sua ocorrência, a mãe 
já tece expectativas, fantasias e demonstra desejos em relação à criança (Aulagnier, 1994; Cramer \& Palácio-Espasa, 1993, Lebovici, 1983/ 1987; Mazet \& Stoleru, 1988/1990). Esses aspectos, que compõem o campo subjetivo da relação mãe-bebê, constituem as representações maternas, que podem ser determinantes para a natureza do relacionamento que a mãe estabelece com seu bebê (Brazelton \& Cramer, 1992; Cramer \& Palácio-Espasa, 1993; Lebovici,1983/1987; Mazet \& Stoleru, 1988/1990).

Também fazem parte de tais representações os aspectos transgeracionais (Lebovici, 1996, 1998), que constituem conflitos associados às gerações anteriores, principalmente às famílias de origem dos pais, e que podem influenciar, mesmo de forma inconsciente, a relação atual da díade mãe-bebê. Da mesma forma, os aspectos intergeracionais (Golse, 2003; Lebovici, Solis-Ponton \& Barriguete, 2004) especificamente ligados às vivências da mãe com a sua própria mãe, são elementos importantes a serem analisados nas representações maternas.

Cabe ressaltar que são encontradas na literatura outras nomenclaturas para designar as representações maternas, tais como percepções ou sentimentos da mãe sobre a criança, sobre si mesma como mãe ou em relação à própria mãe. Essas diferentes denominações buscam destacar, de modo geral, as vivências atuais que norteiam a relação mãe-criança. Convém lembrar que esses aspectos foram apontados pela psicanálise a partir dos trabalhos de Winnicott (1956/2000,1987/2006) sobre a relação mãe-bebê. Esse autor (Winnicott, 1987/2006) abordou a influência das representações maternas na vivência da maternidade, destacando que cada mãe já foi um bebê e traz consigo as lembranças de tê-lo sido. Da mesma forma, tem recordações de que alguém cuidou dela, sendo que essas lembranças podem ajudar ou atrapalhar a sua própria experiência como mãe.

Dentre todos os aspectos que compõem as representações maternas, serão destacadas, neste trabalho, as representações da mãe sobre a sua própria mãe e sobre o bebê. As primeiras devido ao fato de a literatura psicanalítica apontar, de forma unânime, a influência das representações sobre a própria mãe na relação estabelecida pela mãe com a criança (Aulagnier, 1994; Brazelton \& Cramer, 1992; Cramer \& Palácio-Espasa, 1993; Golse, 2003; Lebovici, 1987; Winnicott, 1987/2006). Quanto às segundas, as representações sobre o bebê, ressalta-se que estas ocupam lugar de destaque na Psicanálise, 
e parecem ser o eixo que norteia o mundo representacional materno (Bick, 1964/1987; Cramer \& PalácioEspasa, 1993, Fraiberg, Adelson \& Shapiro, 1975; Golse, 2003; Lebovici, 1987; Lebovici, Solis-Ponton \& Barriguete, 2004; Mazet \& Stoleru, 1988/1990; Winnicott, 1956/2000; 1987/2006).

No que concerne às representações sobre a própria mãe, sabe-se que a mulher, na busca por um modelo materno próprio, poderá reviver com intensidade as experiências vivenciadas com a própria mãe tanto na infância como na atualidade. De fato, o modelo materno de sua própria mãe ocupa lugar de destaque no mundo representacional da maioria das mulheres que passam a exercer a função materna (Aulagnier, 1994).

Ressalta-se que a investigação das representações da mulher sobre a própria mãe possibilita analisar o processo de identificação com ela e sua influência na atual relação mãecriança, demonstrando, assim, o processo de transmissão intergeracional (Golse, 2003, Lebovici, Solis-Ponton, \& Barriguete, 2004), anteriormente mencionado. Nesse processo estão inseridas tanto identificações construtivas da mulher com sua própria mãe, como identificações alienantes (patológicas), sendo que ambas podem repercutir na relação atual mãe-criança (Golse, 2003).

Sobre esse aspecto, uma questão crucial que se coloca para a mulher, independentemente da sua idade, é de 
que forma fará uso dessas identificações na construção da própria identidade materna, visto que a linha divisória entre esses dois tipos de identificação é, às vezes, bastante tênue (Golse, 2003). Assim, percebe-se que as vivências com a própria mãe têm grande influência no exercício da maternidade da futura mãe, que se molda inicialmente em torno de uma tríade psíquica, composta por sua mãe, por ela mesma e pelo bebê (Brazelton \& Cramer, 1992; Lebovici, 1983/1987).

Outra importante representação que compõe o mundo representacional materno, de modo geral mais destacada pela psicanálise, como já citado, refere-se às representaçôes sobre o bebê. Fraiberg, Adelson e Shapiro (1975) foram as pioneiras a considerar as representações da mãe sobre o bebê como eixo central da relação mãebebê, devido à influência destas no desenvolvimento de um possível processo patológico, que pode resultar num relacionamento mãe-criança perturbado ou na formação de sintomas do bebê. Por outro lado, percebe-se que essa investigação, que valoriza os aspectos fantasmáticos da mãe, também poderá apontar elementos positivos, que contribuam para a elaboração da resiliência, a formação de um vínculo seguro e, portanto, a prevenção de um processo psicopatológico da criança (Guedeney \& Lebovici, 1999; Pinto, 2004).

De fato, os aspectos fantasmáticos da mãe sobre o bebê, ilustrados por meio da identificação projetiva, constituem pilares importantes para a construção do senso de identidade por parte do mesmo e também para o seu desenvolvimento psíquico como um todo (Cramer \& PalácioEspasa, 1993). Especificamente sobre esse aspecto, cabe mencionar que as fantasias maternas representam impulsos ou sentimentos (por exemplo, desejos, medos, ansiedades, amor ou mágoa) que dominam a mente materna no momento, e podem ser ilustradas nos cuidados da mãe com a criança (Klein, 1952/1986). Klein (1952/1986) apontou que tais fantasias constituem o conteúdo primário dos processos mentais inconscientes e, por isso, apresentam-se exclusivamente de forma inconsciente. Destacou também que as fantasias inconscientes maternas, demonstradas na identificação primária da mãe com a criança, tornam-se mais elaboradas e passíveis de expressão por meio da experiência da maternidade, vivenciada na relação com o bebê.

A identificação projetiva se apresenta como principal mecanismo que impulsiona tais representações maternas, mostrando como está a identificação da mãe com seu bebê (Bion, 1962/1991; Winnicott, 1956/2000). Sobre essa identificação, Bion (1962/ 1991) descreveu que ela é a base da capacidade de rêverie da mãe, na qual a mesma busca ser continente para as projeções de seu bebê, devolvendo a ele suas angústias de forma modificada. Essas angústias do bebê consti- 
tuem um terror sem nome, até serem acolhidas pelo continente materno. Assim, a partir da capacidade de rêverie, a mãe acolhe as projeções-necessidades do bebê, modificando tais sensações desagradáveis e consolando-o (Golse, 1998).

A identificação da mãe com o bebê já é elaborada pouco a pouco no decorrer da gravidez, a partir da possibilidade de entrada da mulher em um estado que Winnicott (1956/ 2000) denominou preocupação materna primária. Nesse processo, a mãe desenvolve gradativamente um grau de sensibilidade aumentada, direcionando sua atenção para o bebê e renunciando a alguns interesses pessoais em prol dele (Golse, 1998).

As questões mencionadas demonstram que, por meio do processo de identificação mãe-bebê, é possível ter acesso às representações $\mathrm{da}$ mãe sobre a criança, não só na experiência da maternidade propriamente dita, mas também durante a gestação. Cabe mencionar que a relação da mãe com o bebê já existe desde antes da gravidez e está presente nas suas fantasias frente à possibilidade de ter um filho. Desse modo, pode-se dizer que a vida imaginária e fantasmática da mãe na gravidez (e antes dela) constitui a base essencial da relação posterior que ela estabelecerá com o bebê (Mazet \& Stoleru, 1988/1990).

Como parte das representações maternas, especialmente durante a gestação, a futura mãe atribui ao feto características e personalidade própria 
e, assim, começa a se relacionar com ele, iniciando uma vinculação ainda imaginária (Brazelton \& Cramer, 1992; Lebovici, 1983/1987). Nesse sentido, o bebê imaginário corresponde ao bebê fruto do desejo de ser mãe, que é construído durante a gravidez (Lebovici, 1983/ 1987). De qualquer modo, imaginar o bebê representa reconhecê-lo como um ser próprio (Aulagnier, 1990), que, apesar de ser completamente dependente, não pode ser considerado apenas como uma extensão do corpo materno. Essa representação do futuro bebê enquanto ser próprio possibilita à mãe investi-lo afetivamente antes e especialmente a partir do seu nascimento.

Além do bebê imaginário, a mente materna abriga a existência de outras representações sobre o bebê, na qual se destacam o bebê edípico, o bebê fantasmático, o bebê real e o bebê cultural. O bebê edípico (Lebovici, 1983/1987) está ligado diretamente ao inconsciente materno, pois corresponde à história edípica materna, representando os desejos infantis da mãe. Esse bebê representa o desejo de ter tido um filho com o pai, que foi reprimido por conta do declínio do Complexo de Édipo. Quanto ao bebêfantasmático (Soubieux \& Soulé, 2005), é fruto dos fantasmas inconscientes infantis e depende das relações objetais estabelecidas pela mãe. Também é o testemunho da sua organização edipiana e do luto de seus objetos edipianos. Esse bebê parece representar a pré-história materna (Bydlowski, 1988). Já o bebê real é aquele que está em interação com a mãe e mostra suas competências precoces (Lebovici \& Stoleru, 2003), podendo ou não ter características do bebê imaginário. Ele ajudará na reorganização do mundo representacional da mãe, pois ele a está transformando em uma mãe, impulsionando-a a formar novas representações sobre si mesma e a reorganizar as já existentes (Lebovici, 1983/1987), o que levará à reestruturação de sua identidade como mulher, futura mãe, esposa e filha (Brazelton \& Cramer, 1992). Por fim, o bebê cultural remete ao significado da criança de acordo com a cultura da mãe, e está associado a um bebê mítico (Lebovici, 1998).

Outro aspecto que deve ser destacado sobre as representações maternas sobre o bebê refere-se ao legado transgeracional (Lebovici, 1996, 1998) que, como já mencionado, também exerce importante influência nessas representações. No caso, muitas vezes as mães percebem e interpretam determinadas atitudes do bebê de acordo com o legado psíquico inconsciente, que é passado através das gerações (Brazelton \& Cramer, 1992; Lebovici, 1996, 1998). Esse le- 
gado projeta no bebê a história passada da mãe, ativada nessa relação. De modo geral, a transmissão transgeracional (Lebovici, 1996, 1998) faz com que as fantasias maternas sobre o bebê possam assumir três formas: a representação de uma pessoa que teve papel relevante no passado da mãe, a revivência de formas passadas de relacionamento e a representação de um aspecto inconsciente da mãe.

Entretanto, a manifestação do passado da mãe no relacionamento com o bebê é normal e, de certo modo, favorece o estabelecimento do vínculo entre eles. Convém ressaltar que essa manifestação só se torna patológica quando a mãe passa a ver o bebê de forma distorcida (Brazelton \& Cramer, 1991/1992). Esse caráter patológico das representações maternas pode ser observado, dentre outras formas, a partir do desenvolvimento de sintomas psicofuncionais no bebê (Pinto, 2004), que se caracterizam por uma série de manifestações somáticas ou comportamentais, sem causa orgânica, que apontam dificuldades na relação mãe-pai/bebê.

As ideias mencionadas sobre as representações maternas demonstraram a influência destas na relação mãe-criança. Por conta disso, essa temática constitui um importante foco de atenção na clínica pais-bebê, cuja avaliação e intervenção têm por objetivo promover a qualidade da relação dos pais com o bebê (Manieu, 2002), permitindo, em decorrência, 
que a criança se constitua psiquicamente de um modo saudável e harmonioso. Nesse sentido, são citadas a seguir algumas possibilidades de avaliação e de intervenção clínica sobre as representações maternas, derivadas das contribuições psicanalíticas.

\section{Possibilidades de avaliação e intervenção clínica das representações maternas}

$\mathrm{Na}$ perspectiva psicanalítica são encontradas diferentes formas de avaliação e intervenção clínica sobre as representações maternas, derivadas de diferentes perspectivas teóricas. Em relação à avaliação das representações maternas, pode ser citado o Método Bick de Observação de Bebês (Bick, 1964/ 1987). Já quanto à intervenção psicoterapêutica sobre as representações maternas, apresentam-se três formas distintas embasadas psicanaliticamente: o método de associação livre (Freud, 1911/ 1996a), a psicoterapia conjunta pais/ bebê (Cramer \& Palacio-Espasa, 1993; Guedeney \& Lebovici, 1997/ 1999) e a consulta terapêutica (Lebovici, 1998). Salienta-se que esta separação entre avaliação e intervenção é meramente didática, porque muitas vezes a própria avaliação já pode repercutir sobre os sujeitos, caracterizando-se também como uma intervenção. Além disso, para intervir, o profissional inevitavelmente fará uma avaliação inicial, própria de cada técnica. Assim, tanto as formas de avaliação quanto as de intervenção psicoterapêticas aqui apresentadas visam à transformação das representações maternas, quando isso se mostrar necessário.

O Método Bick de Observação de Bebês (Bick, 1964/1987), criado em 1948, foi construído com o objetivo de contribuir para a formação de psicoterapeutas e psicanalistas infantis. Consiste na observação direta de um bebê em seu contexto natural, possibilitando a compreensão das relações do mesmo com a mãe (ou figuras substitutas) em várias situações. Dessa forma, possibilita conhecer o mundo representacional de todos os envolvidos na situação, que inclui as ansiedades, fantasias e defesas de cada um, somadas ainda às representações do observador.

A observação direta do bebê é realizada uma vez por semana, durante uma hora, ao longo dos seus primeiros dois anos de vida. Do método fazem parte três etapas sistemáticas, que consistem na observação, na anotação do que foi observado e na supervisão do material. Assim, após a visita à família, o observador registra por escrito a observação, incluindo todos os detalhes lembrados, bem como os afetos experimentados. Por fim, é por meio da supervisão que ele terá a possibilidade de organizar e compreender o material, dando sentido às vivências observadas, sob o ponto de vista psicanalítico. Essa supervisão é realizada semanalmente em 
grupo e é coordenada por um psicanalista (Oliveira, Menezes, Caron \& Lopes, 2006).

Especificamente quanto à intervenção psicoterapêutica sobre as representações maternas, o método de associação livre (Freud, 1911/1996a) propicia um encadeamento dos conteúdos psíquicos e suas representações, através de recordações e fantasias sobre uma situação vivida no momento presente. Consiste em expor verbalmente e livremente o que vem à mente (associações). No caso específico das representações maternas, inclui as recordações, afetos, fantasias e acontecimentos nos quais emergem os principais conflitos que determinam a relação atual entre a mãe e o bebê, e que são trabalhados na situação analítica propriamente dita, sem um tempo determinado para tal. Quanto à postura do analista, esta se situa no enquadre da neutralidade, que se caracteriza pela escuta imparcial sobre os relatos apresentados, bem como a escassez de participação ativa nas sessões (Manieu, 2002).

Já a psicoterapia conjunta pais / bebêe (Cramer \& Palacio-Espasa, 1993; Guedeney \& Lebovici, 1997/1999) analisa as representações maternas com o objetivo de reelaborar as projeções maternas e modificar as interações patológicas ligadas a elas. Porém, não pretende modificar em profundidade o funcionamento psíquico da mãe, da criança e da díade/tríade, pois tal psicoterapia é de caráter breve e focal. É indicada quando o processo de reconhecimento do filho está bloqueado pelo reaparecimento de conflitos antigos da mãe, que repercutem de forma conflituosa na representação sobre a criança e remetem às identificações alienantes (patológicas) já mencionadas (Golse, 2003).

De acordo com Cramer e Palacio-Espasa (1993) e Guedeney e Lebovici (1997/1999), a possibilidade de se realizar uma psicoterapia breve pais-bebê está atrelada a dois aspectos importantes: a grande mobilidade psíquica que ocorre no período pós-parto e a limitação setorial das psicopatologias mais frequentemente observadas na interação pais-bebê. As sessões habitualmente têm duração de 45 a 50 minutos, podendo se estender ou até ultrapassar os $60 \mathrm{mi}$ nutos. A flexibilidade da duração da sessão visa não interromper as várias associações que geralmente são produzidas e também a permitir a observação de vários modos de interação, segundo os aspectos fantasmáticos que surgirem ou o conflito correspondente. A via de ingresso para o trabalho é a consulta na qual a mãe relata um sintoma da criança e não dela. Esse relato descreve as perturbações 
relacionais estabelecidas a nível diádico (Cramer \& Palacio-Espasa, 1993).

Quanto ao número de sessões, estas variam conforme o caso, mas, em geral, são realizadas de 4 a 12 sessões, com frequência semanal. $\mathrm{O}$ setting deve favorecer a capacidade de associação e a troca entre a díade ou tríade, da forma mais livre possível. O psicoterapeuta é atento à observação visual das trocas entre a mãe e o bebê, limitando suas interpretações ao campo dos conflitos diádicos estabelecidos e sua relação com a história da mãe (Cramer \& Palacio-Espasa, 1993).

Por fim, a consulta terapêtica (Lebovici, 1998), que tem por base a abordagem desenvolvida por Winnicott (1971/1984), explora a história familiar da criança, tendo também como objetivo identificar as representações da mãe/pai sobre ela e sua influência na relação diádica e/ou triádica, por meio da narrativa parental. No caso específico das representações maternas, observa-se principalmente a comunicação que se estabelece entre mãe e criança, através das emoções da mãe, que, por meio de sua preocupação materna, possibilita a tradução dos sinais do bebê e a satisfação de suas necessidades (Lebovici, Solis-Ponton, \& Barriguete, 2004).

Diferentemente da psicoterapia breve pais-bebê, nessa modalidade de intervenção as sessões são pouco numerosas (de três a quatro aproxima- 
damente), porém, às vezes, com maior duração: uma hora ou mais. Essa intervenção visa mobilizar psiquicamente os pais e a criança, podendo provocar o desaparecimento do sintoma presente na criança e/ou na relação pais-bebê. Também, quando necessário, possibilita a indicação de um tratamento mais prolongado (Lebovici, Solis-Ponton, \& Barriguete, 2004).

As diferentes formas de avaliação e intervenção psicoterapêutica sobre as representações maternas na psicanálise têm o objetivo comum de melhorar a qualidade da relação mãecriança, como já enfatizado. Com base nesse aspecto, percebe-se que a análise dessas representações ocorre, em geral, a partir da investigação das representações da mãe sobre o bebê, o que não exclui a consideração de outros tipos de representações como, por exemplo, sobre a própria mãe ou sobre ela mesma como mãe. Desse modo, pode-se dizer que as técnicas apresentadas analisam as representações maternas a partir de um entrelaçamento de representações que compõem o mundo representacional materno, tendo como eixo principal a investigação das representações sobre o bebê.

\section{Considerações finais}

O presente trabalho teve como objetivo abordar as representações maternas, destacando as representações da mulher sobre a própria mãe e sobre o bebê. Também buscou apresentar algumas possibilidades de avaliação e intervenção clínica sobre essas representações, segundo a perspectiva psicanalítica. $O$ interesse para a realização desse estudo surgiu da necessidade de detalhar o conceito "representações maternas", assim como sua aplicação no contexto clínico.

A partir do exposto, foi possível constatar a complexidade desse conceito, cuja definição vem sendo desenvolvida por diferentes autores psicanalíticos desde Freud. Entretanto, percebeu-se que a análise das representações maternas tem por base as formulações gerais de Freud sobre representação, sendo enfatizado o cunho inconsciente das mesmas pelos diversos autores que investigaram o tema.

Também foi possível perceber que a investigação das representações maternas, segundo a psicanálise, aponta para as repercussões no processo de identificação da mãe com o bebê, podendo acarretar um processo patológico na criança e/ou na relação da díade, ou, ao contrário, contribuir para a qualidade dessa relação.

A partir das diferentes formas de avaliação e intervenção psicoterapêuticas mencionadas, vê-se o caráter preventivo da investigação precoce de tais representações. Entretanto, apesar de sua relevância já haver sido apontada anteriormente, nota-se a 
necessidade de uma maior atenção a essa temática, não somente no contexto clínico, mas também no contexto acadêmico, cuja abordagem do tema se mostra recente (por ex., Batthika, Faria \& Kopelman, 2007; Gomes, Piccinini \& Prado, 2009; Piccinini, Ferrari, Levandowski, Lopes, \& De Nardi, 2003).

Desse modo, com o presente estudo, espera-se principalmente estimular a realização de novos trabalhos sobre o tema, com o intuito de promover intercâmbio de informações entre clínicos e pesquisadores. Com isso, fomentar novas discussões e avanços na teorização, na avaliação e na terapêutica das representações maternas.

MATERNAL REPRESENTATIONS: THORETICAL ASPECTS AND POSSIBILITIES OF EVALUATION AND CLINICAL INTERVENTION

\begin{abstract}
Maternal representations include mother's expectations, fantasies and desires about baby, as well as transgenerational aspects related to. This study aims to introduce these representations, focusing on woman's representations about the own mother and baby. It also shows possibilities of evaluation and clinical intervention about these representations, in a psychoanalytical perspective. It was highlighted the investigation of maternal representations as an important instrument of parent-infant clinic, belping to improve the quality of this relationship. Then, their investigation could be more employed not only in clinical, but also in research context.
\end{abstract}

Index terms: maternal representations; psychoanalysis; mother-infant relationship. 
REPRESENTACIONES MATERNAS: ASPECTOS TEÓRICOS Y POSIBILIDADES DE EVALUACIÓN T INTERVENCIÓN CLÍNICA

\section{RESUMEN}

Las representaciones maternas incluyen las expectativas, las fantasias y los deseos de la madre sobre el bebé, así como los aspectos transgeneracionales relacionados a eso. El objectivo de este trabajo es introducir esas representaciones, especialmente las representaciones de la mujer sobre la propria madre y sobre el bebé. Además, son presentadas algunas posibilidades de evaluación y intervención clínica sobre estas representaciones, según la perspectiva psicoanalitica. Cabe señalar que la investigación de las representaciones maternas es una herramienta importante en la clinica padres-bebé, ayudando a mejorar la calidad de esta relación. Entonces, suya investigación podría ser más frecuente en el contexto clínico y académico.

Palabras clave: representaciones maternas; psicoanalysis; relación madre-bebé.

\section{REFERÊNCIAS}

Almeida, S., Ataíde, A., Nascimento, M. J. Pires, P., \& Silva, P. C. (2003). Representações mentais maternas: Um caso de trigêmeos. Análise Psicológica, 21, 103110.

Aulagnier, P. (1990). Um Intérprete em Busca de Sentido (R. Steffen, trad.). São Paulo: Escuta. (Trabalho original publicado em 1986).

Aulagnier, P. (1994). Nacimiento de um cuerpo, inicio de una historia. In L. Hornstein (Org.), Cuerpo, História, Interpretación: Piera Aulagnier - De lo Originario al Proyeto Identificatório (pp. 117-170). Buenos Aires: Paidós.

Batthika, E. C., Faria, M. C. C. de, \& Kopelman, B. I. (2007). As representações maternas acerca do bebê que nasce com doenças orgânicas graves. Psicologia: Teoria e Pesquisa, 23(1), 17-24.

Bick, E. (1987). Notes on infant observation in psycho-analytic training. In M. Hanis \& E. Bick (Orgs.), Collected Papers of Martha Hanis and Esther Bick (pp. 240-256). Great Britain: The Roland Hanis Education Trust. (Trabalho original publicado em 1964).

Bion, W. R. (1991). O Aprender com a Experiência (P. D. Côrrea, trad.). Rio de Janeiro: Imago. (Trabalho original publicado em 1962).

Brazelton, T. B., \& Cramer, B. (1992). As Primeiras Relações (M. B. Cipolla, trad.). São Paulo: Martins Fontes. (Trabalho original publicado em 1991).

Bydlowski, M. (1998). La Dette de Vie. Itinéaire Psychanalytique de la Maternité. Paris: PUF.

Caropreso, F. (2003). As origens do conceito de inconsciente psíquico na teoria freudiana. Natureza Humana: Revista Internacional de Filosofia e Práticas Psicoterápicas, 5(2), 329-350.

Caropreso, F. (2008). A relação entre a percepção e a representação nos primórdios da metapsicologia freudiana. Psicologia em Estudo, 13(4), 723-732.

Cramer, B., \& Palácio-Espasa, F. (1993). Técnicas Psicoterápicas Mãe/Bebê: Estudos Clínicos e Técnicos (F. F. Settineri, trad.). Porto Alegre: Artes Médicas. 
Fraiberg, S., Adelson, E., \& Shapiro, V. (1975). Ghosts in the nursery: A psychoanalytic approach to the problems of impaired infant-mother relationships. Journal of the American Academy of Child Psychiatry, 14, 387-421.

Freud, S. (1996a). Formulações sobre os dois princípios do funcionamento mental. In Edição Standard Brasileira das Obras Psicológicas Completas de Sigmund Freud (J. Salomão, trad., Vol. 12, pp. 233-244). Rio de Janeiro: Imago. (Trabalho original publicado em 1911).

Freud, S. (1996b). Sobre o narcisismo: Uma introdução. In Edição Standard Brasileira das Obras Psicologicas Completas de Sigmund Freud (J. Salomão, trad., vol. 14, pp. 77-113). Rio de Janeiro: Imago. (Trabalho original publicado em 1914).

Freud, S. (1996c). O Inconsciente. In Edição Standard Brasileira das Obras Psicológicas Completas de Sigmund Frend (J. Salomão, trad., vol. 14, pp. 165-209). Rio de Janeiro: Imago. (Trabalho original publicado em 1915).

Golse, B. (1998). O Desenvolvimento Afetivo e Intelectual da Crianşa (M. L. Homem, trad.). Porto Alegre: Artmed. (Trabalho original publicado em 1985).

Golse, B. (2003). Transmitir a transmissão: Um ponto em comum entre as diferentes terapias conjuntas pais-criança. In Sobre a Psicoterapia Pais-Bebê: Narratividade, Filiação e Transmissão (pp. 59-75), São Paulo: Casa do Psicólogo.

Gomes, A. G., Piccinini, C. A., \& Prado, L. C. (2009). Psicoterapia pais-bebê no contexto de malformação do bebê: Repercussões no olhar da mãe acerca do desenvolvimento do bebê. Revista de Psiquiatria do Rio Grande do Sul, 31(2), 95-104.

Green, A. (1990). Conferências Brasileiras: Metapsicologia dos Limites. Rio de Janeiro: Imago.

Guedeney, A., \& Lebovici, S. (1999). Intervencoões Psicoterápicas Pais/Bebê (P. C. Ramos, trad.). Porto Alegre: Artmed. (Trabalho original publicado em 1997).
Klein, M. (1982). Os Progressos da Psicanálise (A. Cabral, trad.). Rio de Janeiro: Zahar. (Trabalho original publicado em 1952).

Laplanche, J., \& Pontalis, J. B. (2008). Vocabulário da Psicanálise (P. Tamen, trad.). São Paulo: Martins Fontes. (Trabalho original publicado em 1967).

Lebovici, S. (1987). O Bebê, a Mãe e o Psicanalista. (F. Vidal, trad.). Porto Alegre: Artes Médicas. (Trabalho original publicado em 1983).

Lebovici, S. (1996). La transmission intergénérationnelle ou quelques considérations sur l'utilité de l'étude de l'arbre de vie dans les consulations thérapeutiques parents/bebé. In M. Dugat (Org.), Troubles Relationnels Pére-Mére/ Bebé: Quels Soins (pp. 19-28). Ranonville St Agne: Erès.

Lebovici, S. (1998). L'arbre de vie. Les psychotherapies psychanalytiques. Journal de Psychanalyse deL'Enfant, 221, 98-127.

Lebovici, S., \& Stoleru, M. (2003). Le Nourrisson, la Mère et le Psychanalyste: Les Interations Précoces. Paris: Bayard.

Lebovici, S., Solis-Ponton, L., \& Barriguete, J. A. (2004). A árvore da vida ou a empatia metaforizante: $\mathrm{O}$ enactment. In SolisPonton (Org.), Ser pai, ser mãe - parentalidade: um desafio para o terceiro milênio. Uma homenagem internacional a Serge Lebovici (pp. 41-46). São Paulo: Casa do Psicólogo.

Manieu, M. A. (2002). Estúdio Comparativo de las Representaciones Maternas durante el Tercer Trimestre de la Gestácion e Incidencia de la Ecografia em su Estabelecimiento: Embarazos Únicos, Normales, Gemelares Normales y Únicos Patológicos. Tesis Doctoral en Psicopatologia Infanto Juvenil, Departament de Psicologia de la Salut i Social, Universitat Autônoma de Barcelona. Espanha.

Mazet, P., \& Stoleru, S. (1990). Manual de Psicopatologia do Recém-Nascido (F. F. Settineri, trad.). Porto Alegre: Artes Médicas. (Trabalho original publicado em 1988).

Munhoz, J. M. H. (2009). O que representa a representação? Revista Brasileira de Psicanálise, 43(2), 77-85. 


\section{Artigo}

Oliveira, L. M., Menezes, C. C., Caron, N. A., \& Lopes, R. C. S. (2006). O método Bick de observação de bebês como método de pesquisa. Psicologia Clínica, 18(2), 77-96.

Piccinini, C. A., Ferrari, A. G., Levandowski, D. C., Lopes, R. C. S., \& De Nardi, T. C. (2003). O bebê imaginário e as expectativas quanto ao futuro do filho em gestantes adolescentes e adultas. Interações, 8(16), 81-108.

Pinto, E. B. (2004). Sintomas psicofuncionais e as consultas terapêuticas pais/ bebê. Estudos de Psicologia, 9(3), 451-457.

Soubieux, M. J., \& Soulé, M. (2005). La Psichiatrie Foetale. Paris: PUF.

Thá, F. (2004). Representação e pensamento na obra freudiana: Preliminares para uma abordagem cognitiva. Ágora: Estudos em Teoria Psicanalitica, 7(11), 109-128.

Wendland, J. (2001). A abordagem clínica das interações pais-bebê: Perspectivas teóricas e metodológicas. Psicologia: Reflexão e Crítica, 14(1), 45-56.

Winniccot, D. W. (1984). Consultas Terapêuticas em Psiquiatria Infantil (J. Cunha, trad.). Rio de Janeiro: Imago. (Trabalho original publicado em 1971).

Winniccot, D. W. (2000). Da Pediatria à Psicanálise: Obras Escolbidas (J. Russo, trad.). Rio de Janeiro: Imago. (Trabalho original publicado em 1956).

Winniccot, D. W. (2006). Os Bebês e suas Mães (J. L. Camargo, trad.). Rio de Janeiro: Martins Fontes. (Trabalho original publicado em 1987).

\section{NOTAS}

1 O presente estudo deriva da Dissertação de Mestrado da primeira autora, realizada sob orientação da segunda autora, intitulada Representações maternas no contexto da maternidade na adolescência, apresentada ao Programa de Pós-Graduação em Psicologia da Universidade do Vale do Rio dos Sinos (UNISINOS) no ano de 2010.

stelacabral.psico@bol.com.br danielal@ufcspa.edu.br

Recebido em maio/ 2010. Aceito em novembro/ 2010. 